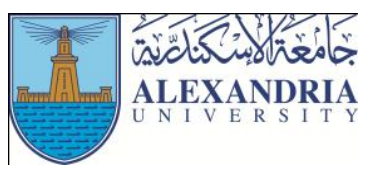

\title{
Comparing the Health-Related Fitness of the (10-12) Years-Old Children in Light of the Variance of Sea Level Altitude
}

\author{
Walid Soliman Ismail El-Saidy ${ }^{1}$ \\ ${ }^{1}$ Assistant Professor at the Physical Education Foundations Department, Faculty of Sport Education for Men at Abu Qir, \\ Alexandria University.
}

\begin{abstract}
This research aims to identify the characteristics of health-related fitness in three provinces in Al-Baha region which vary in the sea level altitude, where Almandaq province is at an elevation of about (2500m), while Alaqeeq province is at an elevation of about (1540m), and Qalwa province is at an elevation of about $(400 \mathrm{~m})$. The research also aims to determine the value, the significance and the direction of differences of the characteristics of health-related fitness among the (10-12) years-old children in the three provinces in order to identify the effect of the environmental factor on the measurements and tests included in the research procedures, and thus creating standard levels in light of the variance in the sea level altitude. The research was conducted on a sample from three provinces whose characteristics were as follow: Almandaq province $(n=312)$, age $(10.67 \pm 0.50)$, Alaqeeq province $(n=231)$, age $(10.72 \pm 0.44)$, Qalwa province $(n=211)$, $(10.67 \pm 0.31)$. The researcher applied the units of the health-related fitness Gulf test on the three groups, which included several tests as follow: $1200 \mathrm{~m}$ run/walk test, hand grip test, (60 seconds) sit ups while bending the knees, stand and reach test, and measurement of the skin folds thickness in three areas of the body. The results determined the value, the significance and the direction of differences between the three groups and showed that there were significant differences in favor to the residents of the higher locations in all measurements of the research, and thus the construction of standard levels of health-related fitness characteristics was achieved for the research sample.
\end{abstract}

Keywords: health-related fitness, sea level altitude

Introduction and research problem:

$\mathrm{E}$ nvironment is one of the important factors that greatly affect the measurements, shape and structure of the human body and its functions as well, and thus the corporal and physical measurements of individuals vary according to the geographical environment in which they live. The superiority of some human races in certain competitive sport activities is due to the effect of the environment on the corporal and physical characteristics of those races, as the genetic factors determine the path of maturity, while the environmental factors help speeding up or delaying this path, so variation and discrimination between human races appear in the nature of physical growth. (Beall, C. M., 2007) (Hogan, A. M. et. al., 2010) (Verges, C. et. al., 2012)

Scientific studies confirmed that the corporal structure and its effects on the physical aspects vary and differ relatively from one society to another according to the environmental conditions of each community. This was supported by the scientific literature which proved that there are environmental factors that affect the human body and the functions of its organs, such as nutrition, temperature, and increasing or decreasing the height of the sea level. (Espinoza-Navarro, O \& Graú, S. 2014) (Abd elhamid, 1999)

Since the sea level altitude is one of the important environmental factors that have a significant impact on growth with all its manifestations, it also helps emerging many factors that affect the corporal and physical characteristics of individuals, these factors are: the lack of oxygen, lack of temperature, humidity and many other factors that interact with each other and affect the human body directly and indirectly. (Espinoza, O., et. al. 2011)

As the topic of the sea level altitude is important, many researchers and numerous studies have discussed it and its effects. From these studies:

(Kapoor S., 2000) (Colonel PK Roy, 2002) (West, JB, 2006) (Peter Bärtsch, MD et. al., 2007) (Mai Van Hung, 
Sunyoung Pak, 2008) (Ferreira et.al, 2008) (Abha Shrivastava, A. Goyal, KSNegi, 2010) (KT Ozgunen et.al, 2010) (Handrawy, 2011) (M. Faramoushi et.al, 2012) (Espinoza, O \& Graú, S, 2014)

The results of these studies showed the different effects of residency in the highlands and that these effects are worth of research and study, where the physiological effects of residency in the highlands that include the increase of red blood cells, increase of respiration rate, increase of heart beats, change in blood pressure, and many other changes which include corporal, physical and health aspects of the residents of those places.

From the information mentioned above and through the researcher's work in Al-Baha region and its provinces, he identified the geography of the region and found that it is above the sea level by more than $(2500 \mathrm{~m})$, but he also noticed that there is a variation in the sea level altitude between the provinces of Al-Baha, as Almandaq province is at an elevation of about $(2500 \mathrm{~m})$, while Alaqeeq province is at an elevation of about $(1540 \mathrm{~m})$, and Qalwa province is at an elevation of about $(400 \mathrm{~m})$, http://www.zahran.org/vb/showthread.php?t=120988. This variation raised the researcher's desire to study the healthrelated fitness of the (10-12) years-old children of this area in light of this environmental diversity, and thus identifying the significance of differences among the children of this age group regarding the health-related fitness elements, to determine standard levels of these measurements, and to assess the health-related fitness, which is one of the most important physical education goals for its positive correlation with many vital areas for the child such as the scientific achievement, physical growth, and the physical, mental, social and psychological health (Abd Elhak, 2005), then we use these standard levels in the selection process and athletic guidance for the children of this age group in light of the geographical variation of Al-Baha region according to the sea level altitude. Finally we would have valuable results to identify the effects of residency in the highlands on some corporal and physical variables, especially in late childhood, which is the ideal age for motor learning.

\section{Research objectives:}

The research aims to identify the following points:

- The characteristics of health-related fitness of the (10-12) years-old children in light of the variance in sea level altitude of Al-Baha provinces of Almandaq, Alaqeeq, and Qalwa in Saudi Arabia.

- Comparing between the health-related fitness elements of the (10-12) years-old children in light of the variance in sea level altitude of the three provinces.

- Constructing standard levels of the health-related fitness elements of the (10-12) years-old children according to the variance in sea level altitude.

\section{Research questions:}

- What are the characteristics of health-related fitness of the (10-12) years-old children in light of the variance in sea level altitude of Al-Baha provinces of Almandaq, Alaqeeq, and Qalwa in Saudi Arabia?

- What are the significant differences of the health-related fitness elements of the (10-12) years-old children in light of the variance in sea level altitude of the three provinces?

- What are the standard levels of the health-related fitness elements of the (10-12) years-old children according to the variance in sea level altitude?

\section{Methods:}

\section{Subjects:}

The research was conducted on a random sample of elementary school students aged from (10-12) years-old from Al-Baha region. The research sample was represented by three different provinces according to the variation in sea level altitude, where the first sample $(\mathrm{n}=$ 312) was represented by students from Almandaq province which is at elevation of $(2500 \mathrm{~m})$ above sea level, while the second sample $(n=231)$ was from Alaqeeq province which is at elevation of $(1540 \mathrm{~m})$ above sea level, and finally the third sample $(\mathrm{n}=211)$ was from Qalwa province which is at elevation of $(400 \mathrm{~m})$ above sea level. The statistical characterization of the samples in their primary measurements is shown in Table (1). 
Table (1)

Statistical characterization of the three groups of the primary measurements

\begin{tabular}{|c|c|c|c|c|c|c|c|}
\hline Groups & Variables & Mean & S.Td & Min. & Max. & Skew. & Kurt. \\
\hline \multirow{4}{*}{$\begin{array}{l}\text { High Altitude } \\
\qquad \begin{array}{c}(2500 \mathrm{~m}) \\
\mathrm{N}=312\end{array}\end{array}$} & Age (to the nearest month) & 10.67 & 0.50 & 10.00 & 11.80 & 0.76 & -0.05 \\
\hline & Weight (to the nearest kilogram) & 29.93 & 3.32 & 22.00 & 37.00 & -0.16 & -0.09 \\
\hline & Length (to the nearest centimeter) & 1.34 & 0.06 & 1.21 & 1.52 & 0.14 & -0.18 \\
\hline & Body mass index $(\mathrm{Kgm} / \mathrm{m} 2)$ & 16.72 & 2.43 & 10.39 & 22.54 & 0.01 & -0.48 \\
\hline \multirow{4}{*}{$\begin{array}{l}\text { Medium Altitude } \\
\qquad \begin{array}{c}1540 \mathrm{~m})( \\
\mathrm{N}=231\end{array}\end{array}$} & Age (to the nearest month) & 10.72 & 0.44 & 10.10 & 11.50 & 0.61 & -0.08 \\
\hline & Weight (to the nearest kilogram) & 31.92 & 3.57 & 25.00 & 43.00 & 0.61 & 0.24 \\
\hline & Length (to the nearest centimeter) & 1.32 & 0.07 & 1.17 & 1.52 & 0.20 & -0.02 \\
\hline & Body mass index $(\mathrm{Kgm} / \mathrm{m} 2)$ & 18.53 & 2.95 & 12.71 & 27.10 & 0.55 & 0.21 \\
\hline \multirow{3}{*}{$\begin{array}{l}\text { Low Altitude } \\
\qquad \begin{array}{l}(400 \mathrm{~m}) \\
\mathrm{N}=211\end{array}\end{array}$} & Age (to the nearest month) & 10.67 & 0.31 & 10.20 & 11.40 & 0.64 & -0.47 \\
\hline & Length (to the nearest centimeter) & 1.29 & 0.06 & 1.15 & 1.46 & 0.01 & 0.16 \\
\hline & Body mass index $(\mathrm{Kgm} / \mathrm{m} 2)$ & 19.80 & 3.40 & 12.67 & 30.74 & 0.49 & -0.23 \\
\hline
\end{tabular}

\section{Measurements Procedures:}

- Fitness test according to the guiding manual of the health-related fitness Gulf test:

Since health-related fitness features the elements that are related to or affect health, and it is the individual's performance ability in a set of tests that indicates the extent of cardio-respiratory efficiency, the corporal structure, strength, endurance and flexibility of the skeletal muscle, so the battery contains elements that represent (corporal structure, musculoskeletal fitness, endurance and arthropod flexibility) (Anne et al., 2014) (Vancampfort et al., 2014)

The data was collected by applying the health-related fitness Gulf battery for the (7-18) years-old children, as its scientific transactions were verified in the Gulf region, according to the guiding manual of health-related fitness Gulf test, which included the following tests and measurements: (1) $1200 \mathrm{~m}$ run/walk test, to measure the endurance (or cardiorespiratory fitness), (2) hand grip test, to measure the muscle strength, (3) (60 seconds) sit ups while bending the knees, to measure the strength and endurance of the abdominal muscles, (4) stand and reach test (flexibility box), to measure the muscle flexibility of the back thighs and lower back, and (5) measurement of the skin folds thickness in three areas of the body (brachial triceps muscle area, the area below the scapula bone, and the inner middle area (medial muscle) of the leg to measure the corporal construction). (2001 Al-hazaa) Attachment (1)

Prior to applying the tests, the researcher has got permissions to facilitate applying the study, and thus preparing the appropriate questionnaire forms to the research procedures. The researcher also trained his assistants well on how to conduct the tests, and excluded the sick children and those who cannot undergo the tests as well as the athletic students who may affect the measurement result. The individuals were notified not to eat for a period of not less than two hours before applying the tests, that the phase prior to application included warming-up for (10-15 min.). The tests were applied in light of the guiding manual to the health-related fitness Gulf test for the (7-18) years-old children according to the following order: measuring the height, weight and thickness of skin folds, then measuring the hand grip, followed by sit ups, stand and reach test, and finally $1200 \mathrm{~m}$ run/walk test. Table (2) shows the statistical characterization of the three groups of the research regarding the health-related fitness elements according to the variation in sea level altitude. After applying the analysis of variance (ANOVA) test, the researcher was able to determine the significance of differences between the three regions regarding the health-related fitness elements, which are illustrated in Table (3). To determine the direction of these differences, and based on Table (4), the researcher used Scheffe test and then calculated the size of the effect to illustrate the strength of the statistical significance of the differences between the three groups.

In light of applying the research measurements on the total sample, the researcher achieved the standard ( $t$ ) values for the measurements, Attachment (2), where the standard (t) values were calculated for the $1200 \mathrm{~m}$ run/walk test (min.), and only the average hand grip test (Newton) was conducted as it depends on measuring the strength of the right and the left fists, (60 seconds) sit ups (number), stand and reach test $(\mathrm{cm})$. He also used only the total of the skin folds thickness of the three regions ( $\mathrm{mm}$ ) because he 
depends on the sum of the three areas under discussion. In light of the standard values, the total standard $(\mathrm{t})$ values of the total sample were calculated, and the levels where the health-related fitness in Al-Baha region could be evaluated in light of the variation in sea level altitude in the three provinces were determined. Table (5) shows the minimum and maximum ranges of the raw values and the corresponding $(t)$ values to the total sample and the total of the standard $(\mathrm{t})$ values of the research measurements, while Table (6) shows the classifying levels of the total research sample in light of the total number of the standard (t) values of the research measurements.

\section{Statistical treatments:}

Statistical Package for Social Sciences (SPss), Version (20) was used to obtain the following variables: (arithmetic mean, standard deviation, the least and the greatest values, skewness, kurtosis, (t) value, one-way analysis of variance, Scheffe test for the least significant difference, squared ETA to calculate the size of effect)

\section{Results:}

Table (2)

Statistical characterization of the three groups regarding the health-related fitness elements according to the variation of sea level altitude

\begin{tabular}{|c|c|c|c|c|c|c|c|}
\hline Groups & Statistics & Mean & S.Td & Min. & Max. & Skew. & Kurt. \\
\hline \multirow{9}{*}{$\begin{array}{l}\text { High Altitude } \\
\qquad \begin{array}{c}(2500 \mathrm{~m}) \\
\mathrm{N}=312\end{array}\end{array}$} & $1200 \mathrm{~m}$ run/walk test (min.) & 6.38 & 0.47 & 5.20 & 7.60 & -0.81 & 0.12 \\
\hline & Right hand grip (Newton) & 11.61 & 1.22 & 8.00 & 15.00 & 0.24 & -0.47 \\
\hline & Left hand grip (Newton) & 10.07 & 1.29 & 7.00 & 13.00 & 0.25 & -0.49 \\
\hline & (60 seconds) sit ups (number) & 23.58 & 2.33 & 18.00 & 30.00 & 0.07 & 0.33 \\
\hline & Stand and reach $(\mathrm{cm})$ & 4.78 & 1.28 & 1.00 & 9.00 & 0.38 & -0.35 \\
\hline & Measurement of the skin thickness of the brachial triceps muscle ( $\mathrm{mm})$ & 5.50 & 0.76 & 4.10 & 7.40 & 0.55 & -0.24 \\
\hline & Measurement of the skin thickness of the area below the scapula bone (mm) & 6.06 & 0.76 & 4.20 & 7.23 & -0.60 & -0.94 \\
\hline & $\begin{array}{l}\text { Measurement of the skin thickness of the inner middle area (medial muscle) of } \\
\text { the leg }(\mathrm{mm})\end{array}$ & 6.61 & 0.76 & 4.75 & 7.78 & -0.60 & -0.94 \\
\hline & Total of the skin folds thickness for the three areas (mm) & 18.17 & 1.76 & 13.55 & 21.91 & -0.53 & -0.51 \\
\hline \multirow{10}{*}{$\begin{array}{c}\text { Medium } \\
\text { Altitude } \\
(1540 \mathrm{~m}) \\
\mathrm{N}=231\end{array}$} & $1200 \mathrm{~m}$ run/walk test (min.) & 6.76 & 0.85 & 5.20 & 8.75 & 0.25 & -0.46 \\
\hline & Right hand grip (Newton) & 10.23 & 1.67 & 7.00 & 14.00 & 0.02 & -0.40 \\
\hline & Left hand grip (Newton) & 8.97 & 1.90 & 5.00 & 13.00 & -0.37 & -0.62 \\
\hline & Average hand grip (Newton) & 9.60 & 1.70 & 6.00 & 13.50 & -0.06 & -0.54 \\
\hline & (60 seconds) sit ups (number) & 21.26 & 4.50 & 10.00 & 31.00 & -0.23 & -0.68 \\
\hline & Stand and reach $(\mathrm{cm})$ & 3.65 & 1.68 & 1.00 & 8.00 & 0.35 & -0.68 \\
\hline & Measurement of the skin thickness of the brachial triceps muscle (mm) & 6.42 & 1.44 & 4.15 & 10.50 & 0.79 & 0.26 \\
\hline & Measurement of the skin thickness of the area below the scapula bone $(\mathrm{mm})$ & 6.78 & 1.19 & 4.60 & 8.80 & -0.04 & -0.91 \\
\hline & $\begin{array}{l}\text { Measurement of the skin thickness of the inner middle area (medial muscle) of } \\
\text { the leg }(\mathrm{mm})\end{array}$ & 7.05 & 0.99 & 5.15 & 8.58 & -0.24 & -0.09 \\
\hline & Total of the skin folds thickness for the three areas $(\mathrm{mm})$ & 20.24 & 3.03 & 14.25 & 27.33 & 0.05 & -0.61 \\
\hline \multirow{9}{*}{$\begin{array}{l}\text { Low Altitude } \\
\qquad \begin{array}{c}(400 \mathrm{~m}) \\
\mathrm{N}=211\end{array}\end{array}$} & Right hand grip (Newton) & 9.00 & 1.07 & 7.00 & 10.00 & -0.55 & -0.09 \\
\hline & Left hand grip (Newton) & 8.05 & 1.64 & 5.00 & 10.00 & -0.16 & -0.29 \\
\hline & Average hand grip (Newton) & 8.52 & 1.22 & 6.50 & 10.00 & -0.24 & -0.24 \\
\hline & (60 seconds) sit ups (number) & 19.49 & 4.80 & 10.00 & 30.00 & 0.18 & -0.61 \\
\hline & Stand and reach $(\mathrm{cm})$ & 2.65 & 1.11 & 1.00 & 6.00 & 0.97 & 0.72 \\
\hline & Measurement of the skin thickness of the brachial triceps muscle (mm) & 7.55 & 1.33 & 5.15 & 10.50 & 0.43 & -0.74 \\
\hline & Measurement of the skin thickness of the area below the scapula bone $(\mathrm{mm})$ & 7.92 & 0.90 & 6.10 & 8.80 & -0.92 & -0.69 \\
\hline & $\begin{array}{l}\text { Measurement of the skin thickness of the inner middle area (medial muscle) of } \\
\text { the leg }(\mathrm{mm})\end{array}$ & 7.60 & 0.58 & 6.20 & 8.58 & -0.32 & 0.03 \\
\hline & Total of the skin folds thickness for the three areas (mm) & 23.07 & 1.66 & 19.00 & 27.33 & 0.08 & 0.05 \\
\hline
\end{tabular}


Table (3)

One-way analysis of variance the three groups regarding the health-related fitness elements according to the variation of sea level altitude

\begin{tabular}{|c|c|c|c|c|c|c|c|c|}
\hline Variables $\quad$ Statistics $n=754$ & $\begin{array}{l}\text { Source of } \\
\text { variation }\end{array}$ & df & $\begin{array}{l}\text { Sum of } \\
\text { Squares }\end{array}$ & $\begin{array}{l}\text { Mean } \\
\text { Square }\end{array}$ & $\mathrm{F}$ & Sig. & $\begin{array}{l}\text { Effect Size } \\
\text { Value }\end{array}$ & $\begin{array}{l}\text { Effect Size } \\
\text { Level }\end{array}$ \\
\hline \multirow{3}{*}{ Age } & Between Groups & 2 & .47 & .23 & \multirow{3}{*}{1.24} & \multirow{3}{*}{.29} & \multirow{3}{*}{0.06} & \multirow{3}{*}{ Weak } \\
\hline & Within Groups & 751 & 141.22 & .19 & & & & \\
\hline & Total & 753 & 141.69 & & & & & \\
\hline \multirow{3}{*}{$1200 \mathrm{~m}$ run/walk test (min.) } & Between Groups & 2 & 72.63 & 36.31 & \multirow{3}{*}{86.08} & \multirow{3}{*}{.00} & \multirow{3}{*}{0.48} & \multirow{3}{*}{ Great } \\
\hline & Within Groups & 751 & 316.81 & .42 & & & & \\
\hline & Total & 753 & 389.44 & & & & & \\
\hline \multirow{3}{*}{ Right hand grip (Newton) } & Between Groups & 2 & 876.84 & 438.42 & \multirow{3}{*}{244.23} & \multirow{3}{*}{.00} & \multirow{3}{*}{0.81} & \multirow{3}{*}{ Great } \\
\hline & Within Groups & 751 & 1348.13 & 1.80 & & & & \\
\hline & Total & 753 & 2224.97 & & & & & \\
\hline \multirow{3}{*}{ Left hand grip (Newton) } & Between Groups & 2 & 528.15 & 264.08 & \multirow{3}{*}{103.32} & \multirow{3}{*}{.00} & \multirow{3}{*}{0.52} & \multirow{3}{*}{ Great } \\
\hline & Within Groups & 751 & 1919.45 & 2.56 & & & & \\
\hline & Total & 753 & 2447.61 & & & & & \\
\hline \multirow{3}{*}{ Average hand grip (Newton) } & Between Groups & 2 & 691.42 & 345.71 & \multirow{3}{*}{179.14} & \multirow{3}{*}{.00} & \multirow{3}{*}{0.69} & \multirow{3}{*}{ Great } \\
\hline & Within Groups & 751 & 1449.34 & 1.93 & & & & \\
\hline & Total & 753 & 2140.76 & & & & & \\
\hline \multirow{3}{*}{ (60 seconds) sit ups (number) } & Between Groups & 2 & 2175.78 & 1087.89 & \multirow{3}{*}{73.13} & \multirow{3}{*}{.00} & & \\
\hline & Within Groups & 751 & 11171.29 & 14.88 & & & 0.44 & Great \\
\hline & Total & 753 & 13347.07 & & & & & \\
\hline & Between Groups & 2 & 577.93 & 288.96 & 153.22 & .00 & & \\
\hline Stand and reach $(\mathrm{cm})$ & Within Groups & 751 & 1416.33 & 1.89 & & & 0.64 & Great \\
\hline & Total & 753 & 1994.26 & & & & & \\
\hline $\begin{array}{l}\text { Measurement of the skin thickness of the } \\
\text { brachial triceps muscle (mm) }\end{array}$ & Within Groups & 751 & 1027.05 & 1.37 & & & 0.72 & Great \\
\hline & Total & 753 & 1553.35 & & & & & \\
\hline & Between Groups & 2 & 435.29 & 217.65 & 242.45 & .00 & & \\
\hline $\begin{array}{l}\text { Measurement of the skin thickness of the area } \\
\text { below the scapula bone (mm) }\end{array}$ & Within Groups & 751 & 674.18 & .90 & & & 0.80 & Great \\
\hline & Total & 753 & 1109.48 & & & & & \\
\hline & Between Groups & 2 & 124.39 & 62.20 & 98.92 & .00 & & \\
\hline inner middle area (medial muscle) of the leg & Within Groups & 751 & 472.20 & .63 & & & 0.51 & Great \\
\hline & Total & 753 & 596.59 & & & & & \\
\hline & Between Groups & 2 & 3017.27 & 1508.64 & & & & \\
\hline Total of the skin folds thickness for the three & Within Groups & 751 & 3648.32 & 4.86 & 310.55 & .00 & 0.91 & Great \\
\hline & Total & 753 & 6665.59 & & & & & \\
\hline
\end{tabular}


Table (4)

Significance of differences of the three health-related fitness elements using Scheffe test

\begin{tabular}{|c|c|c|c|c|}
\hline \multirow[b]{2}{*}{ Variables } & \multirow[b]{2}{*}{ Groups } & \multirow[b]{2}{*}{ Mean } & \multicolumn{2}{|c|}{ Mean Differences } \\
\hline & & & $\begin{array}{l}\text { Medium Altitude } \\
\qquad(1540 \mathrm{~m})\end{array}$ & $\begin{array}{l}\text { Low Altitude } \\
\qquad(400 \mathrm{~m})\end{array}$ \\
\hline \multirow[t]{2}{*}{$1200 \mathrm{~m}$ run/walk test (min.) } & Medium Altitude $(1540 \mathrm{~m})$ & 6.76 & & $-.38 *$ \\
\hline & Low Altitude (400m) & 7.14 & & \\
\hline \multirow{3}{*}{ Right hand grip (Newton) } & High Altitude (2500m) & 11.61 & $1.38^{*}$ & $2.61 *$ \\
\hline & Medium Altitude (1540m) & 10.23 & & $1.23418 *$ \\
\hline & Low Altitude (400m) & 9.00 & & \\
\hline \multirow{3}{*}{ Left hand grip (Newton) } & High Altitude (2500m) & 10.07 & $1.10^{*}$ & $2.02 *$ \\
\hline & Medium Altitude (1540m) & 8.97 & & $.91 *$ \\
\hline & Low Altitude (400m) & 8.05 & & \\
\hline \multirow{3}{*}{ Average hand grip (Newton) } & High Altitude (2500m) & 10.84 & $1.24 *$ & $2.32 *$ \\
\hline & Medium Altitude $(1540 \mathrm{~m})$ & 9.60 & & $1.07 *$ \\
\hline & Low Altitude (400m) & 8.52 & & \\
\hline \multirow{3}{*}{ (60 seconds) sit ups (number) } & High Altitude (2500m) & 23.58 & $2.32 *$ & $4.09 *$ \\
\hline & Medium Altitude (1540m) & 21.26 & & $1.77 *$ \\
\hline & Low Altitude (400m) & 19.49 & & \\
\hline \multirow{3}{*}{ Stand and reach $(\mathrm{cm})$} & High Altitude (2500m) & 4.78 & $1.12 *$ & $2.12 *$ \\
\hline & Medium Altitude $(1540 \mathrm{~m})$ & 3.65 & & $1.00 *$ \\
\hline & Low Altitude (400m) & 2.65 & & \\
\hline \multirow{2}{*}{$\begin{array}{l}\text { Measurement of the skin thickness of the brachial triceps } \\
\text { muscle }(\mathrm{mm})\end{array}$} & High Altitude (2500m) & 5.50 & $-.91 *$ & $-2.04 *$ \\
\hline & Medium Altitude (1540m) & 6.42 & & $-1.13^{*}$ \\
\hline \multirow{3}{*}{$\begin{array}{l}\text { Measurement of the skin thickness of the area below the } \\
\text { scapula bone }(\mathrm{mm})\end{array}$} & High Altitude (2500m) & 6.06 & $-.72 *$ & $-1.86^{*}$ \\
\hline & Medium Altitude (1540m) & 6.78 & & $-1.14 *$ \\
\hline & Low Altitude (400m) & 7.92 & & \\
\hline \multirow{3}{*}{$\begin{array}{l}\text { Measurement of the skin thickness of the inner middle } \\
\text { area (medial muscle) of the leg }(\mathrm{mm})\end{array}$} & High Altitude (2500m) & 6.61 & $-.44 *$ & $-.99 *$ \\
\hline & Medium Altitude $(1540 \mathrm{~m})$ & 7.05 & & $-.56 *$ \\
\hline & Low Altitude (400m) & 7.60 & & \\
\hline \multirow{3}{*}{ Total of the skin folds thickness for the three areas (mm) } & High Altitude (2500m) & 18.17 & $-2.07 *$ & $-4.89 *$ \\
\hline & Medium Altitude (1540m) & 20.24 & & $-2.83 *$ \\
\hline & Low Altitude (400m) & 23.07 & & \\
\hline
\end{tabular}

Significant at the 0.05 level

for the group 
Table (5)

Minimum and maximum levels of the raw and the corresponding $(\mathrm{t})$ values of the total sample, and the total of the standard ( $\mathrm{t}$ ) values of the research measurements

\begin{tabular}{|c|c|c|c|c|}
\hline \multirow{2}{*}{$\begin{array}{l}\text { Variables } \\
\mathrm{N}=754\end{array}$} & \multicolumn{2}{|c|}{ Minimum level } & \multicolumn{2}{|c|}{ Maximum level } \\
\hline & Raw value & (t) value & Raw value & (t) value \\
\hline $1200 \mathrm{~m}$ run/walk test (min.) & 8.75 & 21.63 & 5.20 & 70.99 \\
\hline Average hand grip (Newton) & 6.00 & 27.39 & 14.00 & 74.84 \\
\hline (60 seconds) sit ups (number) & 10.00 & 22.16 & 31.00 & 72.04 \\
\hline Stand and reach $(\mathrm{cm})$ & 1.00 & 32.56 & 9.00 & 80.00 \\
\hline Total of the skin folds thickness for the three areas $(\mathrm{mm})$ & 27.33 & 25.96 & 13.55 & 72.28 \\
\hline Total of the standard $(t)$ values of the research measurements & --- & 129.70 & --- & 370.15 \\
\hline
\end{tabular}

Table (6)

Characterizing levels of the total sample in light of the total standard $(\mathrm{t})$ values for the research measurements

\begin{tabular}{|c|c|}
\hline Total of the standard (t) values & Level \\
\hline Less than 203.29 & Weak \\
\hline From 203.29 to less than 240.98 & Acceptable \\
\hline From 240.98 to less than 260.97 & Good \\
\hline From 260.97 to less than 290.82 & Excellent \\
\hline More than 290.82 & . \\
\hline
\end{tabular}

\section{Discussion:}

This study aimed to identify the health-related fitness characteristics of the (10-12) years-old children in three areas which vary in the sea level altitude. These areas were Almandaq province, which is at an elevation of about $(2500 \mathrm{~m})$, Alaqeeq province, which is at an elevation of about $(1540 \mathrm{~m})$, and Qalwa province which is at an elevation of about $(400 \mathrm{~m})$. The researcher was able to apply the research measurements and thus reaching the health-related fitness characteristics for the three regions, as shown in the results of table (2).

To determine the significance of differences between the three regions regarding the health-related fitness characteristics, and according to the results of table (3) of the one-way analysis of variation between the three regions regarding the health-related fitness elements, as well as table (4) of the significance of differences using Scheffe test, there were significant differences in all health-related fitness variables in favor to the children who live in Almandaq, where the highest altitude of sea level, followed by those who live in Alaqeeq with its medium altitude, and finally Qalwa with the lowest sea level altitude. The results also showed that the effect size is great in the differences between the three regions in all of the research variables. The researcher found that this result explains what (Fulco, CS, et al., 2013) has proved, as he pointed that living on the highlands features a set of changes in the cardiovascular and respiratory systems, in addition to changes in the musculoskeletal system as a result of living in locations higher than the sea level.

Studies also show that the inhabitants who live in areas above sea level are completely adapted and get higher levels of gas exchange than those who live at the sea level, this can be attributed to the continuous lack of oxygen in which these people live and this increases the pulmonary blood pressure and blood vessel density, which helps improve the pulmonary perfusion. This explains the differences between the three research groups in the variables of endurance and muscular endurance according to the sea level. Wyatt, F. B. (2014)

Scientific studies also showed that the skeletal muscle is adapted when a person lives at a high elevation above sea level, without any change in the mechanical efficiency of the muscles. (Lundby, C. c., Et al., 2007)

The study of (Igor, R., et al., 2011) showed that there is an increase in the density of capillaries within muscle cells and increased blood pressure due to living in the highlands, which explains the result of the current study that there are differences between the three research groups in the muscle strength in light of the elevation from sea level due to the effect of these variables on the level of muscle strength and endurance.

The results of this study are consistent with the study of (Vikal Tripathy, Ranjan Gupt), which showed that the inhabitants of the higher locations are affected by the sea level in some physical variables with a decrease in the 
total length and weight compared to their peers in the same age who live at lower elevations as they are characterized by more height and weight and more skin folds as well. From this point the researcher can interpret the superiority of the inhabitants of high locations regarding the element of flexibility, which is inversely related with the mass of fat in the body.

According to the results of this study, the researcher saw that it is necessary to build standard levels for the (10-12) years-old children in Al-Baha region in light of the variation in sea level altitude and its obvious effects on the health-related variables under study.

Based on the results of tables (5) and (6), the standard (t) values corresponding to the raw values of health-related fitness tests were calculated; thus, the total number of standard values by which the health-related fitness level of the (10-12) years-old children in Al-Baha region were calculated in light of the variation in sea level altitude of the different provinces.

\section{Conclusion:}

The researcher, through the current study, was able to answer the research questions by identifying the healthrelated fitness characteristics of the three research samples in light of the variation in sea level altitude. Adding to this, the present study has achieved a new scientific addition by determining the significance of differences among the three research groups, its directions and its effect size, which showed that the variables associated with living in the highlands positively affect the healthrelated fitness of the inhabitants of those areas, and thus we can take advantage of these results in the classification process, selection and sport guidance. In order to implement these findings, the researcher has constructed standard levels of the raw values of the total research sample in the variables under study in order to evaluate the health-related fitness level; thus, both physical education teachers and trainers have a reliable scientific criterion in evaluating the health-related fitness level of the research sample for the mentioned age group in Al-Baha region.

\section{Recommendation:}

In light of the current research results, the researcher recommends using these results in evaluating, selecting and guiding the (10-12) years-old children in Al-Baha region according to the standard values achieved by the researcher, as well as using the results in directing the sport training process for the children who live at high sea level altitudes to the sports activities, as the study proved that they have the required specifications that serve these activities physically.

\section{References:}

1- Beall, C. M.(2007). Two routes to functional adaptation: Tibetan and Andean high-altitude natives. Proc. Natl. Acad. Sci. U. S. A,. 104(Suppl. 1):8655-60.

2- Hogan, A. M.; Virués-Ortega, J.; Botti, A. B.; Bucks, R.; Holloway, J. W.; Rose-Zerilli, M. J.; Palmer, L. J.; Webster, R. J;. Baldeweg, T. \& Kirkham, F. J. (2010). Development of aptitude at altitude. Dev. Sci., 13(3):53344.

3- Verges, C. Trastornos por deficit de atención e hiperactividad (TDAH).(2012). Importancia de la visión en el diagnóstico y su tratamiento .2012.Disponible en:http://oftalmologiabarcelona.com/2012/03/14/trastorno s-por-deficit-de-atencione-hiperactividad-tdah-

importancia-de-la-vision-en-el-diagnostico- $\quad$ y-sutratamiento/

4- Espinoza-Navarro, O \& Graú, S.(2014). Effects of High Altitude on Morphophysiological Patterns, Perception and Attention Capacity in Students from Putre (3500 m.a.s.1.) and Arica (2 m.a.s.1.), Chile. Int. J. Morphol,.32(2):593598.

5- Marawan Abdel-Hamid (1999): Tests, measurement and evaluation in physical education, Dar Al-Fikr AlAraby for publication, Amman, Jordan, p. 176

6- Kapoor S. (2000). Body Structure and respiratory efficiency among high Altitude Himalayan populations. J. Hum. Ecol., 11: 101.

7- Colonel PK Roy. (2002). Physiological Adaptation and Anesthesia at High Altitude .indian J.Anaesth.46 (3), 175181.

8- West, J.B. (2006). Human response to extreme altitudes. Integ. Comp. Biol., 46: 25-34.

9- Peter Bärtsch, MD; J. Simon R. Gibbs, MD, FRCP.(2007). Effect of Altitude on the Heart and the Lungs.

file://C:/Users/pc\%20world/Downloads/2191.full.pdf.

10- Mai Van Hung, Sunyoung Pak.(2008). The impact of environment on morphological and physical indexes of Vietnamese and South Korean students. VNU Journal of Science, Natural Sciences and Technology 24 50-55.

11- Ferreira I. et al.(2006). Environmental correlates of physical activity in youth- a review and update. Speobesity reviews (8), 129-154. 
12- Abha Shrivastava, A. Goyal, K.S.Negi.(2010). Effect of High Altitude on Hematological Parameters, Indian J. Prev. Soc. Med. Vol. 41 No.1\& 2.

13- Ozgunen K. T. et.al. (2010). Effect of hot environmental conditions on physical activity patterns and temperature response of football players, Scand J Med Sci Sports: 20 (Suppl. 3): 140-147.

14- Mohamed Hendawy (2011): The effect of difference in environment temperature on the consumed energy of physical effort, Journal of Al-Nagah University for Human Sciences Researches, vol. 25 , no. 3

15- Faramoushi M. et.al, (2012). The Effect of Altitude on Lung Function of Male Athletes, Annals of Biological Research, 3 (1):313-321.

16- Espinoza-Navarro, O.; Díaz, J.; Rodríguez, H. \& Moreno, A. (2011). Effects of altitude on anthropometric and physiological patterns in Aymara and non-Aymara population between 18 and 65 years in the province of Parinacota Chile (3.700 masl). Int. J. Morphol., 29(1):3440.

17- Abdel-Haq Emad Saleh (2005): Comparative study for the effect of two training programs to develop the healthrelated fitness level for the students of physical education department, Al-Nagah National University and the Technical College of Palestine, Journal of the educational and psychological sciences, Bahrain University, vol. 6, no. 4, Kingdom of Bahrain.

18- Anne. T., Hanne. D., Tuva., Moseng and Inger. H (2014). Health-Related Physical Fitness Measures: Reference Values and Reference Equations for Use in Clinical Practice, Archives of Physical Medicine and Rehabilitation, 95 (7). 1366-1373.
19- Vancampfort. D.,Amber. D.,Johan V.,Matthias. L.,Andrew. S.,Guido. P., Adriaens. A.,Marc. D and Probst. M (2014). Health related quality of life, physical fitness and physical activity participation in treatment-seeking obese persons with and without binge eating disorder, Psychiatry Research, 216 (1), 30, 97-102.

20- Hazzaa bin Muhammad Al-Hazzaa (2001): Guiding manual for the health-related fitness Gulf test, 1st version, Gulf committee for fitness, p. 19

21- Fulco, C. S., Beldleman, B. A., \& Muza, S. R. (2013). Effectiveness of Preacclimatization Strategies for HighAltitude Exposure. Exercise \& Sport Sciences Reviews, 41(1), 55-63.

22- Wyatt, F. B. (2014). Physiological Responses to Altitude: A Brief Review. Journal Of Exercise Physiology Online, 17(1), 90-96.

23- Lundby, C. C., Calbet, J. L., Sander, M. M., van Hall, G. G., Mazzeo, R. S., Stray-Gundersen, J. J., \& Levine, B. D. (2007). Exercise economy does not change after acclimatization to moderate to very high altitude. Scandinavian Journal Of Medicine \& Science In Sports, 17(3), 281-291.

24- Igor, R., Vladimir, I., Milos, M., \& Goran, B. (2011). New tendencies in the application of altitude training in sport preparation. Journal Of Physical Education \& Sport / Citius Altius Fortius, 11(2), 200-204.

25- Vikal Tripathy, Ranjan Gupta (2007). Growth among Tibetans at high and low altitudes in India, American Journal of Human Biology, Volume 19, Issue 6 November/December 2007, Pages 789-800

26- http://www.zahran.org/vb/showthread.php?t=120988 